\title{
Student Performance on an E-Learning Platform: Mixed Method Approach
}

\author{
$\underline{\text { https://doi.org/10.3991/ijet.v15i02.11646 }}$ \\ Slavko Rakic ${ }^{(凶)}$, Nemanja Tasic, Ugljesa Marjanovic \\ University of Novi Sad, Novi Sad, Serbia \\ slavkorakic@uns.ac.rs \\ Selver Softic, Egon Lüftenegger, Ioan Turcin \\ CAMPUS 02 University of Applied Sciences, Graz, Austria
}

\begin{abstract}
E-learning is considered a leading application of digital technologies in educational systems. The aim of the paper is to explore the utilization and impact of digital technologies on an e-learning platform. For this purpose, research was conducted at the Moodle learning management system. Data from the e-learning platform were empirically evaluated in order to find key indicators of student performance in different courses. Student success with the elearning system was evaluated using a mixed-method: Social Network Analysis, K-Means Clustering, and Multiple Linear Regression. The research was conducted at the University of Novi Sad, Faculty of Technical Sciences, Serbia. The results indicate a significant relationship between the performance of students and the use of digital educational resources from the e-learning platform.
\end{abstract}

Keywords-Moodle Learning Management System, E-learning, Social Network Analysis, student performance.

\section{$1 \quad$ Introduction}

The application of new technologies (i.e. e-learning) has recorded growth in recent years [1]. Electronic learning environment provides meaningful contexts that combine skills and knowledge which are available to students [2]. Researchers have also stated that students consistently scored higher grades and higher knowledge level with online tools than with the face-to-face teaching [1]-[3]. McKnight et al. [4] argue that higher education institutions need to develop a strategy if willing to move from traditional towards e-learning. For this process, two aspects need to be considered - the observation of student performance on an e-learning platform, and the satisfaction of students [4]. Social Network Analysis (SNA) is one of the emerging fields of research for extracting useful information from social network data (i.e. e-learning platforms) [5]. For the research presented in this paper, a two-mode network was used, where nodes are students and ties are the frequency of resources usage by students. To address this network, the following model has been proposed in Figure 1 [6]. 


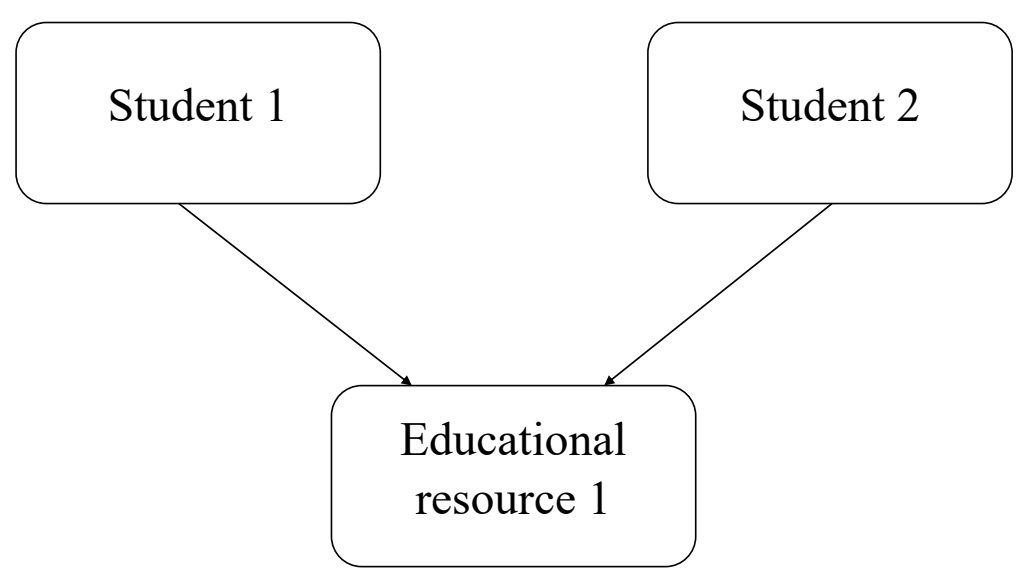

Fig. 1. Connections between students via resources on the e-learning platform [6]

In this paper, authors present research on the application of the SNA method in a Learning Management System (i.e. Moodle). The research was conducted in two courses with 42 students at the study programs of Engineering Management and Engineering of Information Systems at the University of Novi Sad, Serbia. This study measured the relationship between student performance and the frequency of use of educational resources from the e-learning platform. Additionally, authors conducted $\mathrm{K}$-means clustering based upon resource views and achieved student scores, and tested the predictability of student success using multiple linear regression.

\section{Literature Review}

More recently, with the development of new technologies and availability of the internet, teaching and learning have been drastically transformed from the traditional model to the model where students have access to a wide variety of resources online [7] [8], [9]. In the last decade, a real need has been recognized for a more comprehensive definition, measurement and comparison of student performance when using traditional methods and when using e-learning methods [10][11][12]. In one study, students achieved significantly better results with homework based on web technologies than with paper-and-pencil homework [13]. Moreover, research findings showed that students that used Integrating Interactive Whiteboard in their teaching groups had higher scores than groups that used traditional projectors and projection screen during class [14]. However, Morgan et al. [15] provide persuasive evidence that graduates of online accounting programs, on average, have significantly lower six-year average graduation rates than the students that take identical accounting programs set face-toface. Moreover, early analysis highlights a collection of digital disjuncture and disruptions that range from low-level annoyances to more substantial interruptions and obstacles in an e-learning environment [16] [17]-[19]. In Turkey, members of the scien- 
tific community intend to use e-learning technologies mainly to improve their efficiency of teaching since it has the strongest direct effect on student performance [20]. In an e-learning environment, student engagement and use of resources in learning activities is a crucial requirement for excellent performance [21], [22]. Hence, the following research question was proposed

RQ1: What is the relationship between student success and use of resources on the e-learning platform in different courses?

In recent years, the major challenge for every teacher, besides student performance on the e-learning platform, is the question how centrality in a learning network affects the success of students [6]-[16]. Prior study found that students with high centrality are the most active, prestigious, powerful, and more visible than marginal students in the network [24]. Rizzuto [25] assumed that more centrally situated learners tend to get higher final grades. However, Dowell [26] presented that students with high performance and those with central positions in the network are not necessarily the same individuals. Hence, the following research question was proposed

RQ2: How much is centrality in a network in correlation with student success?

If administrators would like to give a suitable content for particular students, they need to make classification and clustering based on the students' characteristics [26]. Authors have used K-Means clustering in their research to classify students' learning activities using e-learning, so as to show clusters of sudents' activities and improve student performance [27]. Previous studies [28], [29] investigated the application of clustering techniques to find groups of students with similar preferences, according to which students focus on different types of information and show different performances in an educational process. Clustering in higher education is used for classifying students by their academic performance [30]. Hence, the following research question was proposed

RQ3: Do students with similar performance form the same cluster?

\section{$3 \quad$ Methodology}

\subsection{Data collection}

The full sample comprised 42 students from two courses: E-business at the Engineering of Information Systems (EIS) study program and E-business at the Engineering Management (EM) study program. To present the interdependent relationship between the learner's success and use of resources on the e-learning platform, the authors used direct observation for a collection of data [21], [31]. In this study, binary forms of the data are presented. The binary data describe whether a student did $(+1)$ or did not (0) use educational resources from a specific section of the course. For example, in the course of E-Business at the Engineering Management, each section specifies its starting number (e.g. R1, R2, R3 to R9) and digital educational resources within the section are marked with R11, R12, R13, R14, R21, R22, R23, R24, R31 and to R94. The course E-business in the LMS consists of 9 sections and 4 resources in eve- 
ry section. Therefore, 36 educational resources are presented in this instance. For example, R31 represents the first resource from the third section, and R92 represents the second resource from the ninth section. The number of students included in this course was 22. Students in this course were labeled with a combination of letters and numbers ranging from $\mathrm{S} 1$ to $\mathrm{S} 22$. A sociogram was used to view the collected data in the SNA method. Table 1 shows the shortened review of the sociogram derived from the experiment.

Table 1. Sociogram in the E-business course at the Engineering Management

\begin{tabular}{|l|c|c|c|c|c|c|c|c|c|}
\hline & R1.1 & R1.2 & R1.3 & R1.4 & R2.1 & R2.2 & R2.3 & .. & R9.4 \\
\hline S1 & 1 & 1 & 1 & 1 & 1 & 1 & 1 & 1 & 1 \\
\hline S2 & 1 & 1 & 1 & 1 & 1 & 1 & 1 & 0 & 0 \\
\hline S3 & 1 & 1 & 1 & 1 & 0 & 1 & 1 & 1 & 1 \\
\hline S4 & 1 & 1 & 1 & 1 & 1 & 1 & 1 & 1 & 1 \\
\hline S5 & 0 & 0 & 0 & 0 & 0 & 0 & 1 & 0 & 0 \\
\hline$\ldots$ & 1 & 1 & 1 & 1 & 1 & 1 & 1 & 1 & 0 \\
\hline S22 & 1 & 1 & 1 & 0 & 1 & 1 & 1 & 0 & 0 \\
\hline
\end{tabular}

Given a set of actors or nodes, the full network method (e.g. E-business at the EIS) and the snowball method (e.g. E-business at the EM) of data collection were used in this research. The full network method approach yields the maximum of information [32]. This method requires collecting information about each actor's ties with all other actors [32]. The snowball method begins with a focal actor or set of actors [32]. Each of these actors is asked to name some or all of their ties to other actors [32].

\subsection{Data analysis}

This paper presents a study for measuring the success of students on the e-learning platform. The focus is on developing student performance through e-learning systems by using a multimethod approach - a combination of social network analysis, Kmeans clustering and tests on predictability of the relation between the number of resource views and the overall score of students using multiple linear regression. The latter two methods address RQ1 and RQ3 and the SNA approach addresses RQ1 and RQ2.

According to the literature [33], [34], the SNA method is highly used in the research related to e-learning. An early study found that SNA reveals the students with the greatest influence and also those students who are isolated or those who assume roles of mediators within the group [35]. This is important since it provides students who attend the same course with valuable information about their roles and how these roles affect their performance. With this in mind, they can conduct analysis on how they can achieve better performance and greater success [34]. There are many different types of social networks that can be studied. This case has two sets of actors; the first set are students and the second set are resources. With two-mode data, researchers can examine how macro-structures (e.g. e-learning platforms) affect interactions 
among students [6]. Furthermore, the tools of two-mode analysis could be applied to LMS data to see if students can be classified according to similarity in their use of resources, simultaneously with classifying network images in terms of the success of those who use the same resources [6]. In this paper, the researchers create a data set of student-by-student ties, measuring the strength of the tie between each pair of students by the frequency of use of the same learning resource. Eigenvector centrality and node-level regression between eigenvector centrality and student success will be measured on the networks.

K-Means and linear regression as methods of prediction and evaluation of student performance have already been well-established [36]. Previous studies [37] analyzed student performance using K-Means and the deterministic model. The results of the analysis have been used as assistance in academic planning for evaluation of student performance during specific semesters and steps that need to be taken to improve student performance with the next batch of students. Borgavakar and Shrivastava [30] used K-Means clustering to analyze and evaluate student performance on the basis of class test, mid test and final test. In this way, they tried to prevent students from failing the final exam. In this research K-Means was used to check whether groups of students can be distinguished based upon the resource usage and overall achieved score in the course. This method offers the answer to RQ3.

Linear regression models represent a common method of confirming model assumptions. For instance, prior research used multiple linear regression to successfully validate a proposed framework to administer the prediction of student academic performance [37]. Another study used a regression model that bases the prediction of student performance on several tasks assigned throughout the duration of a course [38]. In this study we developed a linear regression model based on usage of the assigned online learning resources and measured its quality by classification and regression coefficients. We used the insights from this endeavor to answer the RQ1.

\section{$4 \quad$ Results}

The results of the research were analyzed using the SNA method in UCINET [39] program to examine the data and generate the graph. The K-Means and linear regression analysis were conducted by means of the Python "scipy" and "sklearn" toolkit and using some additional packages such as "pandas", "numpy" and ,seaborn”.

\subsection{SNA analysis}

Figures 2 and 3 depict the student network in the courses of E-business at the EM study program and E-business at the EM IS study program. In Figure 2, red circles represent students, and blue squares represent educational resources in the E-business course (EM). 


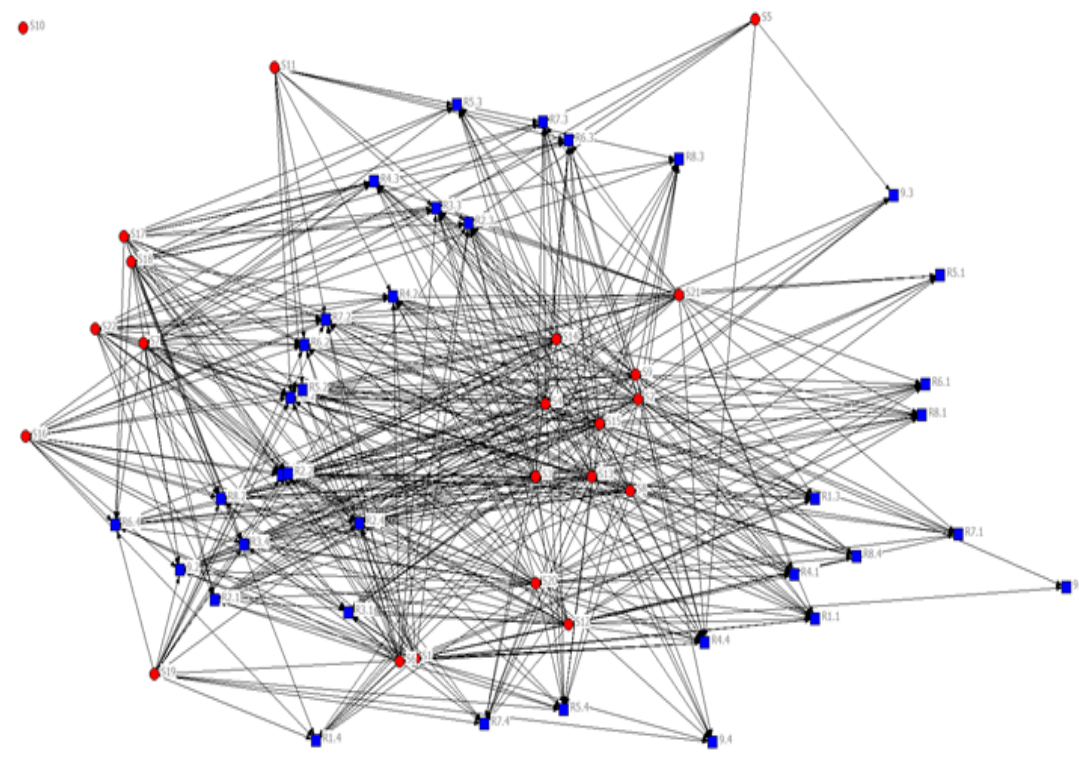

Fig. 2. Social network between students and resources in the E- business EM course

It should be noted that student S10 is disconnected from the network since this student does not use any educational resources. Table 2 presents Eigenvector centrality in the student network in the E-business EM course.

Table 2. Eigenvector centrality of E-Business at the Engineering Management

\begin{tabular}{|l|c|c|c|}
\hline \multicolumn{1}{|c|}{ Student } & Eigenvector & Student & Eigenvector \\
\hline S1 & 0.22 & S12 & 0.206 \\
\hline S2 & 0.286 & $\mathrm{~S} 13$ & 0.27 \\
\hline S3 & 0.263 & $\mathrm{~S} 14$ & 0.241 \\
\hline S4 & 0.252 & $\mathrm{~S} 15$ & 0.279 \\
\hline S5 & 0.046 & $\mathrm{~S} 16$ & 0.168 \\
\hline S6 & 0.223 & $\mathrm{~S} 17$ & 0.164 \\
\hline S7 & 0.219 & $\mathrm{~S} 18$ & 0.187 \\
\hline S8 & 0.231 & $\mathrm{~S} 19$ & 0.16 \\
\hline S9 & 0.264 & $\mathrm{~S} 20$ & 0.242 \\
\hline S10 & 0 & $\mathrm{~S} 21$ & 0.217 \\
\hline S11 & 0.1 & $\mathrm{~S} 22$ & 0.181 \\
\hline
\end{tabular}

Students 'grades are presented in Table 3. Their identities are hidden and labeled. Students with fewer than 50 points failed the exam (i.e. S5 and S11). Students with more than 50 points passed the exam (i.e. 51 - 60 points achieved grade $6,61-70$ grade 7, 71 - 80 grade 8,81 - 90 grade 9 and 91 - 100 grade 10). 
Table 3. Grades of students in the E-Business EM course

\begin{tabular}{|l|c|}
\hline \multicolumn{1}{|c|}{ Student } & Grade \\
\hline S11, S5 & $0-50$ \\
\hline S17, S10 & $51-60$ \\
\hline S7, S19, S14, S21 & $61-70$ \\
\hline S2, S12, S6, S18 & $71-80$ \\
\hline S1, S9, S3, S22, S20 & $81-90$ \\
\hline S4, S16, S8, S13, S15 & $91-100$ \\
\hline
\end{tabular}

The authors measured node-level regression between eigenvector centrality and student achievements. They obtained a R2 value of 0.51 for $* 0.001$, indicating a strong positive correlation between the two metrics. Figure 3 depicts the student network in the E- business EIS course. In Figure 3, red circles represent students, and blue squares represent educational resources in the E- business EIS course.

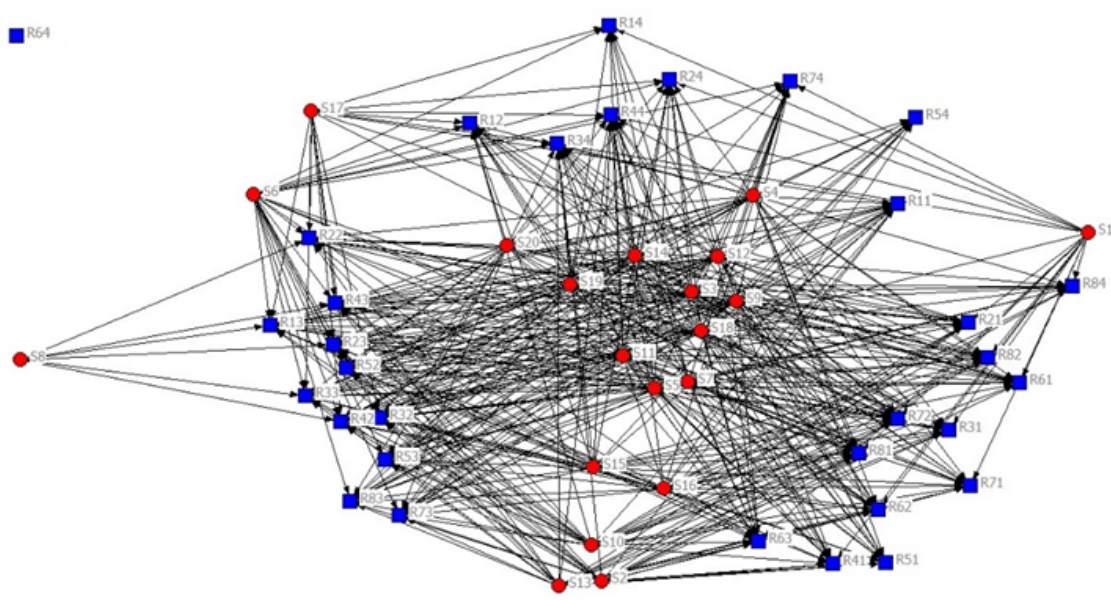

Fig. 3. Social network between students and resources in the E-business EIS course

It should be noted that the educational resource R64 is disconnected from the network since this resource was unreachable to students. Table 5 presents Eigenvector centrality in the student network in the E-business EIS course. 
Table 4. Eigenvector centrality in the E-business EIS course

\begin{tabular}{|l|c|c|c|}
\hline \multicolumn{1}{|c|}{ Student } & Eigenvector & Student & Eigenvector \\
\hline S1 & 0.143 & S11 & 0.255 \\
\hline S2 & 0.202 & S12 & 0.259 \\
\hline S3 & 0.267 & S13 & 0.202 \\
\hline S4 & 0.219 & S14 & 0.252 \\
\hline S5 & 0.257 & S15 & 0.241 \\
\hline S6 & 0.187 & S16 & 0.23 \\
\hline S7 & 0.246 & $\mathrm{~S} 17$ & 0.143 \\
\hline S8 & 0.057 & $\mathrm{~S} 18$ & 0.263 \\
\hline S9 & 0.246 & $\mathrm{~S} 19$ & 0.239 \\
\hline S10 & 0.216 & $\mathrm{~S} 20$ & 0.232 \\
\hline
\end{tabular}

Students'grades are presented in Table 5. Their identities are hidden and labeled.

Table 5. Grades of students of E-business at the EIS course

\begin{tabular}{|l|c|}
\hline \multicolumn{1}{|c|}{ Student } & Grade \\
\hline S8, S17 & $0-50$ \\
\hline S1, S6 & $51-60$ \\
\hline S2, S10 & $61-70$ \\
\hline S20 & $71-80$ \\
\hline S13, S16, S19 & $81-90$ \\
\hline S3, S14, S12, S7, S15, S9, S5, S11, S4, S18 & $91-100$ \\
\hline
\end{tabular}

The authors measured node-level regression between eigenvector centrality and student achievements. They obtained a R2 value of 0.80 for $* 0.001$, indicating a strong positive correlation between the two metrics.

\subsection{K-Means trend analysis}

Authors ran the K-Means on two available data sets in order to check how student scores cluster based on resource views in LMS. For this purpose, authors determined the optimal number of clusters using the"Elbow method". Further subsections describe the findings for data sets.

Figure 4 shows the" Elbow method "estimation for the data from the course on Ebusiness EM. Authors can see that the distortion in five clusters is acceptably low, slightly higher than $10 \%$. 


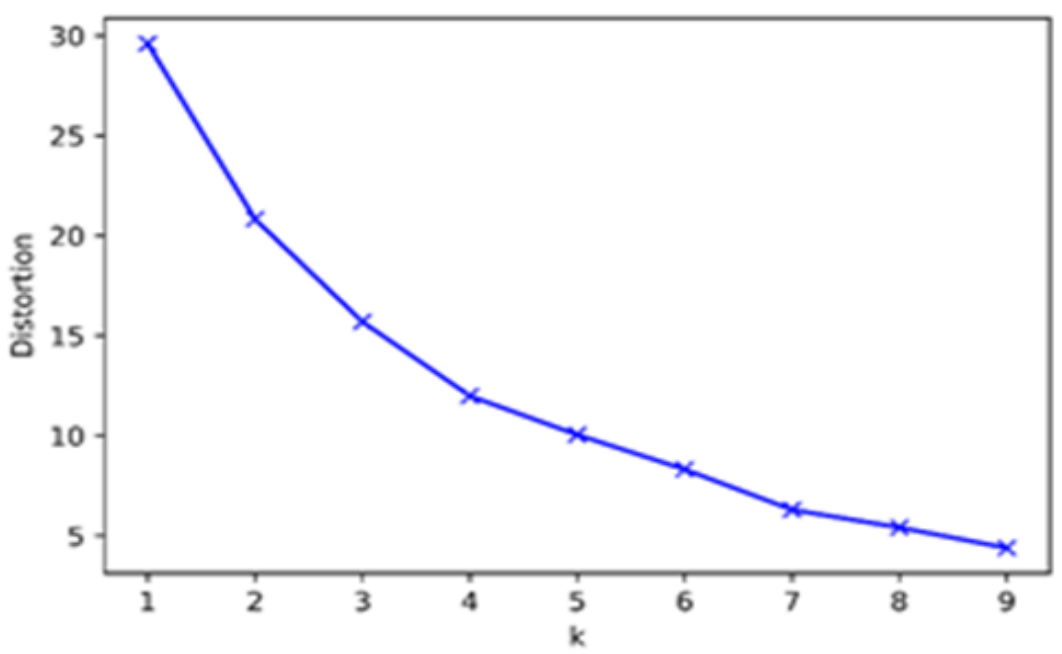

Fig. 4. Elbow method results for the E-business EM course data

Taking the five clusters as the basis for the K-Means leads to the following results regarding the data from the E-business course (see Figure 5.). The clusters are clearly distinguishable and spread along the views/score space. They can be distinguished through different colours: blue, yellow, green, purple and light green. The blue cluster represents the students who did not pass the exam. In other four clusters, we can see nearly linear spread trend depending on the number of views. The trend shows that the more the views, the higher the score with two outliers S2 and S10.

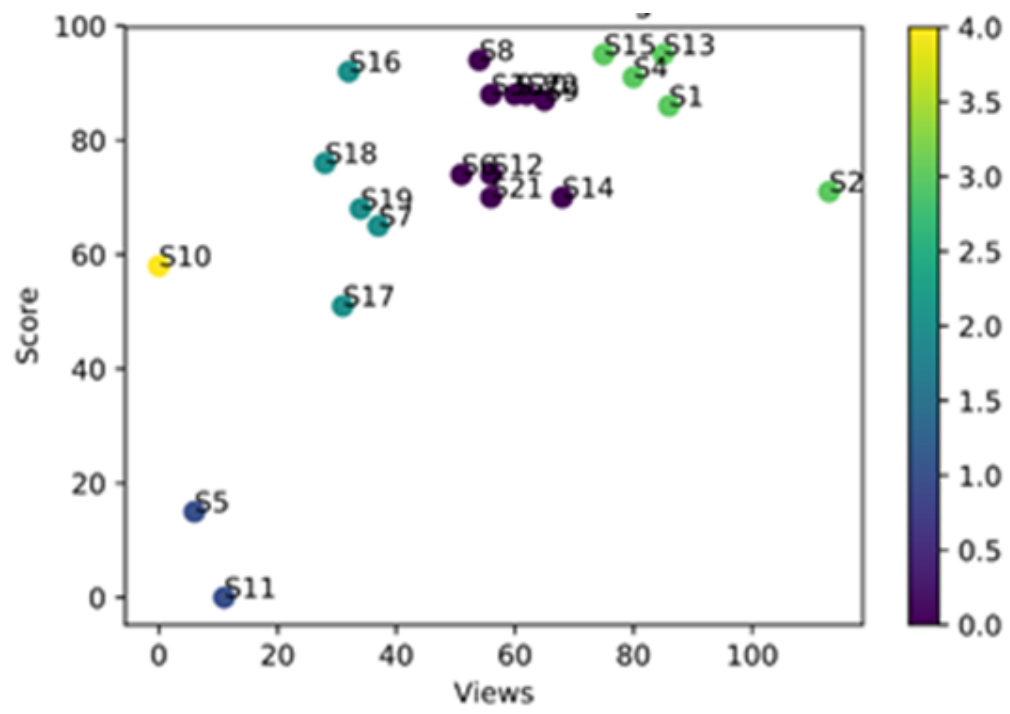

Fig. 5. K-Means clustering results for the E-business EM course data 
We pursued the same approach regarding the"Elbow method" in the course on Ebusiness - EIS. Figure 6 shows the results for this course. Moreover, the choice of five clusters here seems to be a good choice for K-Means clustering.

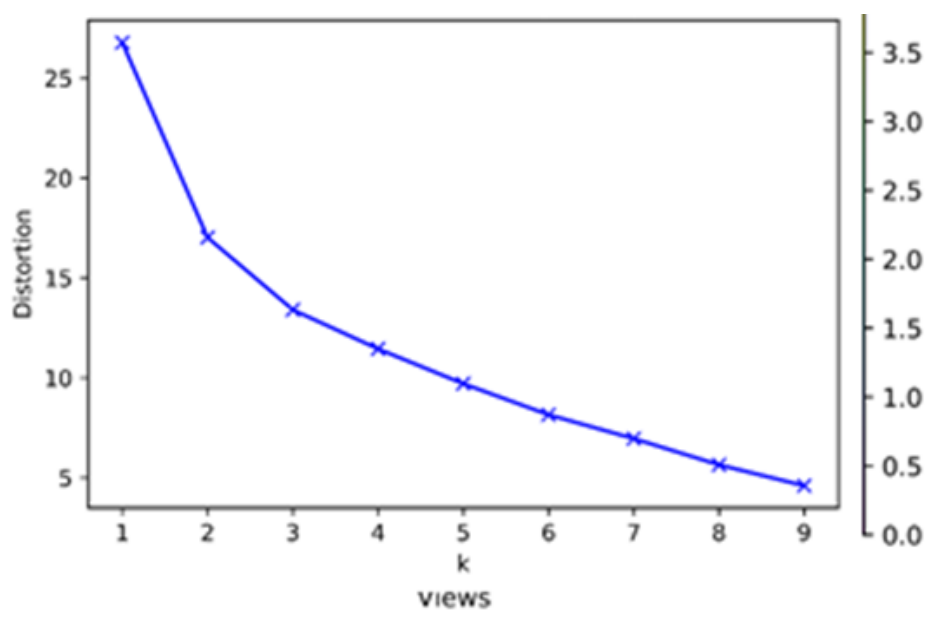

Fig. 6. Elbow method results for the E-business EIS course data

Moreover, in this case the clusters are clearly distinguishable and spread along the views/score space (see Figure 7). They can be distinguished through different colours: blue, yellow, green, purple and light green. The blue cluster members S8 and S17 represent the students who did not pass the exam. In other four clusters we can see a nearly linear spread trend depending on the number of views. Apparently, the trend shows that the number of views correlated with score. The outliers are S2, S12 and S13.

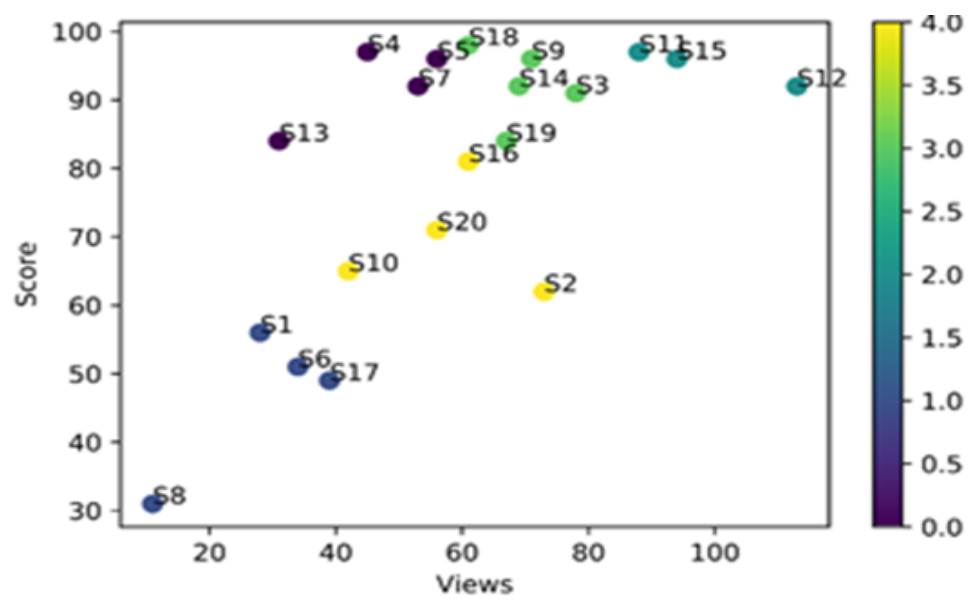

Fig. 7. K-Means clustering results for the E-business EIS course data 


\subsection{Predictability with linear regression}

Furthermore, authors had observed, through K-Means clustering, a trend that there might be linear dependence of the student performance on resource views, we conducted further analysis and observations in order to try to develop a reliable prediction model using the linear regression model based on the data we had. As input we used the matrix containing view count numbers per student and individual resources, and as prediction output, we used students 'scores. Quality values of the model in each of the two courses were: precision, recall/accuracy and F1-score, and R2 for the tested model.

Table 6 shows the average values of classification coefficients for the E-business EM course: Precision, Recall/Accuracy and F-measures as well as regression coefficient R2. Strong classification coefficients lie around the threshold of 0.7. R2 as regression coefficient is 0.9994467 which indicates that the model performs very well.

Table 6. Classification and regression coefficients for the E-business EM course data

\begin{tabular}{|c|c|c|c|}
\hline Precision & Recall/Accuracy & F1 -score & $\mathbf{R}^{\mathbf{2}}$ \\
\hline 0.73 & 0.68 & 0.70 & 0.9994467 \\
\hline
\end{tabular}

Table 7 shows the average values of classification coefficients for the E-business EIS course: Precision, Recall/Accuracy and F-measure as well as regression coefficient R2. Here, strong classification coefficients lie around the threshold of 0.68 . Also, the R2 as regression coefficient which amounts to 0.9989538 performs very well.

Table 7. Classification and regression coefficients for the E-business EIS course data

\begin{tabular}{|c|c|c|c|}
\hline Precision & Recall/ Accuracy & F1 -score & $\mathbf{R}^{\mathbf{2}}$ \\
\hline 0.78 & 0.6 & 0.65 & 0.9989538 \\
\hline
\end{tabular}

\section{Discussion}

The results of the presented study will be analyzed in the following order: for RQ1 based on Figures 2 and 3 and Tables 2-7; for RQ2 based on Tables 2 and 4 and nodelevel regressions; and for RQ3 based on Figures 4-7.

RQ1 was: What is the relationship between student success and use of resources on the e-learning platform in different courses? For different courses there are different types of network. For instance, for two E-business courses, networks are strong and only one node is not in the network. Furthermore, $9 \%$ of students from the E-business course at the EM failed the exam, 10\% of students from the E-business course at the EIS failed the exam. Addressing the RQ1 from the perspective of the predictability experiments conducted on collected data in the two courses and described in section 4.3 , it can be said that the prediction model based on resource views counts in the LMS verified the existence of linear dependence between the resource views and student performance expressed through the overall score. This was measured by clas- 
sification and regression coefficients. In the case of E-business EM course, there is quite high precision of 0.73 , high accuracy of 0.68 and a very good F1-score of 0.7 . The regression coefficient R2 is also very high with 0.9994467 . Moreover, in the case of E-business EIS course, there is high precision of 0.78 , and notable accuracy of 0.6 as well as a very good F1-score of 0.65 . The regression coefficient R2 is also very high with 0.9989538 . Furthermore, in this case, this could be due to the number of samples. The linear relationship, however, is not neglectable. Answering the RQ1 based on the presented findings, it can be said that they confirm the strong correlation between student success and use of resources, indicated through the view counts of resources in the LMS.

RQ2 was: How much is centrality in a network in correlation with student success? The majority of the centrality concepts in graph theory and SNA discuss the most important vertices within a graph [40]. A very usual and very useful approach to twomode data is to convert them into two one-mode data sets, and examine relations within each mode separately [6], [32]. To discuss the results, the authors applied this approach. Prior study presented that eigenvector centrality can be interpreted recursively as positioning that the centrality of each vertex is equal to the sum of the centrality of its neighbors [6], [23]. Moreover, they show that we can envision eigenvector centrality as reflecting the equilibrium outcome of a social process in which each individual sends some power [41]. Furthermore, Besse [42] stated that eigenvector centrality has relations with the social learning network analysis for identifying collaborative work inside Moodle environment. In accordance with previous studies, the authors presented node-level regression between eigenvector centrality and students 'grades in the courses. The authors obtained R2 values of $0.51,0.80$ and 0.81 for the courses E-business EM, E-business EIS and Project Cost Management respectively, for $\mathrm{p}<0.001$. All courses indicate a strong positive correlation between the position in the network and student success. The paper confirms that the position in the network has a positive effect on student performance, like in previous studies [23].

RQ3 was addressed in section 4.2 in K-Means trend analysis. Based upon distribution of scores and using the "Elbow method "which is a method for interpretation and validation of consistency within cluster analysis, it is designed to help to find the appropriate number of clusters in a dataset. In our observations we detected that the number of five clusters for all course data sets represents a reasonable choice according to the "Elbow method". Distortion is always around 10\%. Based on these pre-sets, we ran K-Means. It turned out that we can easily distinguish five clusters with individual outliers that can be explained out of the context. For detailed results, see Figures 5-13. Overall, regarding the RQ3: Are the students with similar performance in the same cluster?, it can be said that the tendency of the analyzed data shows that this question can be answered in an affirmative manner. The K-Means clustering analysis also revealed an existing relation trend between course results and resource views addressed by RQ1, which is a good complement to the findings confirmed by SNA approach and predictability observation with the linear regression model. 


\section{Conclusion}

This research examined the application of the SNA method, K-Means Clustering and Multiple Linear Regression to e-learning. The research was conducted at the University of Novi Sad, Serbia, with groups of students from Engineering Management and Engineering of Information Systems. The results showed that students who achieve the same or similar performance use similar educational resources. Moreover, the results show that all courses indicate a strong positive correlation between the position in the network and student success. Hence, the results showed that the best students are in the center of the network measured by eigenvector centrality. Furthermore, it can be said that the tendency of the analyzed data shows that the students with similar performance are in the same cluster and that the intensity of use of resources correlates with the achieved scores.

Consequently, this paper provides theoretical and practical implications on how the use of educational resources via e-learning platforms impacts a student's success. This study could be helpful to evaluators and teachers of e-learning courses. They could better shape the courses and make clusters of different types of students and focus on things that add value in achieving students' grades and knowledge. Furthermore, this information allows professors to carry out corrective actions and offer new approach to those students who are less participative in a course and have lower grades. Hence, teachers can force interactions (wikis, discussion forums, messages, or chats) between students who have better and lower grades, so that the students with lower grades could increase their success. Finally, teachers and managers for e-learning platforms need to give higher priority to modules within platforms that can motivate students to use them and initiate interactions between students.

This research is limited in scope since it considers only the data set from two courses from the University of Novi Sad. The choice of courses for analysis was made by selecting those in which learning resources were most used. Recently, applying the SNA and K-Means clustering to learning environments and learning problems has attracted a large amount of interest. Accordingly, future research may use these analytical tools in the field of LMS. Moreover, researchers could test the complex interplays between social structures, students' behaviors, and their activities on an elearning platform. The next step is to conduct more comprehensive research with a larger number of different courses on the LMS from different universities. Thereafter, the authors could compare results from different courses and analyze student behavior. Another important aspect to be further analyzed is the success of students with traditional and new learning methods in the same courses. Analyzing student subgroups from the traditional and new learning methods could provide useful information about which courses are better implemented in a traditional way, and which with the help of new methods of learning. 


\section{$7 \quad$ References}

[1] S. Dendir, "An online premium? Characteristics and performance of online versus face-toface students in Principles of Microeconomics," J. Educ. Bus., vol. 91, no. 2, pp. 59-68, 2016. https://doi.org/10.1080/08832323.2015.1110555

[2] L. Kester and P. A. Kirschner, "Effects of fading support on hypertext navigation and performance in student-centered e-learning environments," Interact. Learn. Environ. vol. 17, no. 2, pp. 165-179, 2009. https://doi.org/10.1080/10494820802054992

[3] S. Ozkan and R. Koseler, "Multi-dimensional students' evaluation of e-learning systems in the higher education context: An empirical investigation," Comput. Educ., vol. 53, no. 4, pp. 1285-1296, 2009. https://doi.org/10.1016/j.compedu.2009.06.011

[4] K. McKnight, K. O’Malley, R. Ruzic, M. Horsley, J. J. Franey, and K. Bassett, “Teaching in a digital age: How educators use technology to improve student learning," J. Res. Technol. Educ., vol. 48, no. 3, pp. 194-211, 2016. https://doi.org/10.1080/15391523.2016.1175 $\underline{856}$

[5] M. Gupta and R. Yadav, "Statistical Approach of Social Network in," Int. J. Inf. Technol. Knowl. Manag., vol. 4, no. 1, pp. 43-46, 2011.

[6] S. Rakic, S. Softic, M. Vilkas, B. Lalic, and U. Marjanovic, "Key Indicators for Student Performance at the E-Learning Platform: An Sna Approach," in ICETA 2018 - 16th IEEE International Conference on Emerging eLearning Technologies and Applications, Proceedings, 2018. https://doi.org/10.1109/iceta.2018.8572236

[7] J. T. Nganji, "Towards learner-constructed e-learning environments for effective personal learning experiences,” Behav. Inf. Technol., vol. 37, no. 7, pp. 647-657, 2018. https://doi. org/10.1080/0144929x.2018.1470673

[8] L. Gusel, V. Boskovic, J. Domitner, M. Ficko, and M. Brezocnik, "Genetic programming method for modelling of cup height in deep drawing process," Adv. Prod. Eng. Manag., vol. 13, no. 3, pp. 358-365, 2018. https://doi.org/10.14743/apem2018.3.296

[9] R. Andersson, E. Bridi, Y. P. Baez, M. U. Maldonado, F. A. Forcellini, and F. C. Moraes, "Improvement in public administration services: A Case of business registration process," Int. J. Ind. Eng. Manag., vol. 9, no. 2, pp. 109-120, 2018.

[10] B. Dimitrios, S. Labros, Kakkos Nikolaos, K. Maria, and Koustelios Athanasios, "Traditional Teaching Methods Vs. Teaching Through the Application of Information and Communication Technologies in the Accounting Field: Quo Vadis?," Eur. Sci. J., vol. 9, no. 28, pp. 73-101, 2013.

[11] U. Marjanovic, S. Rakic, and B. Lalic, "Digital Servitization: The Next 'Big Thing' in Manufacturing Industries," in Advances in Production Management Systems, 2019, pp. 510-517. https://doi.org/10.1007/978-3-030-30000-5 63

[12] S. Takakuwa, W. Yang, and H. Nagatsuka, "Learning the procedure on takt production of TPS by methods engineering and simulation," Int. J. Simul. Model. vol. 17, no. 4, pp. 633642, 2018. https://doi.org/10.2507/ijsimm17(4)452

[13] M. Mendicino, L. Razzaq, and N. T. Heffernan, "A comparison of traditional homework to computer-supported homework,” J. Res. Technol. Educ., vol. 41, no. 3, pp. 331-359, 2009. https://doi.org/10.1080/15391523.2009.10782534

[14] K. T. Yang, T. H. Wang, and Y. C. Kao, "How an interactive whiteboard impacts a traditional classroom," Educ. as Chang. vol. 16, no. 2, pp. 313-332, 2012.

[15] J. D. Morgan, "Online Versus Face-to-Face Accounting Education: A Comparison of CPA Exam Outcomes Across Matched Institutions," J. Educ. Bus., vol. 90, no. 8, pp. 420-426, 2015. https://doi.org/10.1080/08832323.2015.1087371 
[16] N. Selwyn, "Digital downsides: exploring university students' negative engagements with digital technology," Teach. High. Educ., vol. 21, no. 8, pp. 1006-1021, 2016. https://doi. org/10.1080/13562517.2016.1213229

[17] S. Gajic and I. Palcic, "A new framework for complexity analysis in international development projects - Results from a Delphi study," Adv. Prod. Eng. Manag., vol. 14, no. 2, pp. 225-238, 2019. https://doi.org/10.14743/apem2019.2.324

[18] J. Raut, S. Mitrović, B. Melović, and T. Lolić, "Social networks as new business concept for enterprises,” Int. J. Ind. Eng. Manag., vol. 9, no. 3, pp. 147-153, 2018.

[19] N. Suzić, E. Sandrin, S. Suzić, C. Forza, A. Trentin, and Z. Anišić, "Implementation guidelines for mass customization: A researcher-oriented view," Int. J. Ind. Eng. Manag., vol. 9, no. 4, pp. 229-243, 2018. https://doi.org/10.1080/09537287.2018.1485983

[20] Sevil Orhan-Özen, "The Effect of Motivation on Student Achievement," in The Factors Effecting Student Achievement, 2017. https://doi.org/10.1007/978-3-319-56083-0 3

[21] U. Marjanovic, M. Delić, and B. Lalic, "Developing a model to assess the success of elearning systems: evidence from a manufacturing company in transitional economy," Inf. Syst. E-bus. Manag., vol. 14, no. 2, pp. 253-272, 2016. https://doi.org/10.1007/s10257$\underline{015-0282-7}$

[22] S. Hewawalpita, S. Herath, I. Perera, and D. Meedeniya, "Effective learning content offering in MOOCs with virtual reality - An exploratory study on learner experience," J. Univers. Comput. Sci., vol. 24, no. 2, pp. 129-148, 2018.

[23] M. S. Rania and A. Halaseh, Studying Learning Networks within. 2014.

[24] H. Cho, G. Gay, B. Davidson, and A. Ingraffea, "Social networks, communication styles, and learning performance in a CSCL community," Comput. Educ., vol. 49, no. 2, pp. 309329, 2007. https://doi.org/10.1016/j.compedu.2005.07.003

[25] T. E. Rizzuto, J. Ledoux, and J. P. Hatala, "It's not just what you know, it's who you know: Testing a model of the relative importance of social networks to academic performance," Soc. Psychol. Educ., vol. 12, no. 2, pp. 175-189, 2009. https://doi.org/10.1007/s 11218-008-9080-0

[26] N. M. M. Dowell et al., "Modeling Learners' Social Centrality and Performance through Language and Discourse," Educ. Data Min. - EDM'15, 2015.

[27] H. L. Sari, D. Suranti, and L. N. Zulita, "Implementation of k-means clustering method for electronic learning model,” J. Phys. Conf. Ser., vol. 930, no. 1, 2017. https://doi.org/10.10 $\underline{88 / 1742-6596 / 930 / 1 / 012021}$

[28] W. Li and Y. Wang, "Research on the performance evaluation model of higher education teachers based on the improved grey clustering analysis method," Int. J. Emerg. Technol. Learn., vol. 10, no. 8, pp. 46-50, 2015. https://doi.org/10.3991/ijet.v10i8.5220

[29] D. Zakrzewska, "Cluster analysis in personalized e-learning systems," Stud. Comput. Intell., vol. 252, pp. 229-250, 2009.

[30] S. P. Borgavakar, "Evaluating Student's Performance using K-Means Clustering," Int. J. Eng. Res. Technol., vol. 6, no. 5, pp. 114-116, 2017.

[31] D. Stefanovic, U. Marjanovic, M. Delić, D. Culibrk, and B. Lalic, "Assessing the success of e-government systems: An employee perspective," Inf. Manag., vol. 53, no. 6, pp. 717726, 2016. https://doi.org/10.1016/j.im.2016.02.007

[32] R. a Hanneman and M. Riddle, "Introduction to Social Network Methods," Riverside, CA Univ. California, Riverside. On-line Textb. vol. 46, no. 7, pp. 5128-30, 2005.

[33] K. L. Cela, M. Á. Sicilia, and S. Sánchez, "Social Network Analysis in E-Learning Environments: A Preliminary Systematic Review," Educ. Psychol. Rev., vol. 27, no. 1, pp. 219-246, 2015. https://doi.org/10.1007/s10648-014-9276-0 
[34] M. de Laat, V. Lally, L. Lipponen, and R.-J. Simons, "Investigating patterns of interaction in networked learning and computer-supported collaborative learning: A role for Social Network Analysis," Int. J. Comput. Collab. Learn., vol. 2, no. 1, pp. 87-103, 2007. https:// doi.org/10.1007/s11412-007-9006-4

[35] P. Vercellone-Smith, K. Jablokow, and C. Friedel, "Characterizing communication networks in a web-based classroom: Cognitive styles and linguistic behavior of selforganizing groups in online discussions," Comput. Educ., vol. 59, no. 2, pp. 222-235, 2012. Wei Liu, "An Improved Back-Propagation Neural Network for the Prediction of College Students' English Performance,” Int. J. Emerg. Technol. Learn., vol. 14, pp. 130 142, 2019. https://doi.org/10.1016/j.compedu.2012.01.006

[36] O. J. Oyelade, O. O. Oladipupo, and I. C. Obagbuwa, “Application of k Means Clustering algorithm for prediction of Students Academic Performance," 2010.

[37] H. Lu and J. Yuan, "Student performance prediction model based on discriminative feature selection,” Int. J. Emerg. Technol. Learn., vol. 13, no. 10, pp. 55-68, 2018. https://doi.org/ 10.3991/ijet.v13i10.9451

[38] S. P. Borgatti, A. Mehra, D. J. Brass, and G. Labianca, "Network Analysis in the Social Sciences," Science (80-. )., vol. 323, no. 5916, pp. 892-895, 2009. https://doi.org/10.1126/ science. 1165821

[39] S. Wasserman and K. Faust, Social network analysis: Methods and applications. 1994.

[40] S. Softic, "Towards identifying collaborative learning groups using social media," Int. J. Emerg. Technol. Learn., vol. 7, no. SPEC. ISSUE 2, pp. 15-21, 2012. https://doi.org/10.39 91/ijet.v7is2.2325

[41] B. Besse et al., "Dendritic cell-derived exosomes as maintenance immunotherapy after first line chemotherapy in NSCLC," Oncoimmunology, vol. 5, no. 4, 2016.

\section{Authors}

Slavko Rakic is a PhD student at the Faculty of Technical Sciences, University of Novi Sad. He is a Teaching Assistant at the Department of Industrial Engineering and Management, University of Novi Sad. His research interest focuses on e-learning, social network analysis, servitization and Industry 4.0.

Selver Softic holds a doctoral degree - a PhD from Informatics at Graz University of Technology. He is a Research Scientist and Lecturer at CAMPUS 02 University of Applied Sciences. His research interest focuses on Learning Analytics, Data Science, Information Systems and Data Visualization in BI and Reporting.

Nemanja Tasic holds doctoral degree - a PhD in Industrial Engineering and Management from University of Novi Sad, Serbia. He is a Professor at the Department of Industrial Engineering and Management, University of Novi Sad. His research interest focuses on higher education systems, Industry 4.0 and efficient management.

Ioan Turcin hold his diploma in Automation Technologies at CAMPUS 02 University of Applied sciences. He is a Research and Teaching Assistant at degree program of Automation Technologies at CAMPUS 02 University of Applied Sciences. His research interest focuses of mechanical engineering, information technologies and electronics.

Egon Lüftenegger holds doctoral degree - a PhD in Information Systems at the School of Industrial Engineering from the Eindhoven University of Technology in the 
Netherlands. He is currently lector in the Network Economy. His research interest focuses on Business Information Systems and business model engineering.

Ugljesa Marjanovic holds doctoral degree - a PhD in Industrial Engineering and Management from University of Novi Sad, Serbia. He is a Professor at the Department of Industrial Engineering and Management, University of Novi Sad. His research interest focuses on e-business, social networks and organizational \& technology innovation in manufacturing companies. He is the Editor-in-Chief of the International Journal of Industrial Engineering and Management.

Article submitted 2019-09-09. Resubmitted 2019-10-11. Final acceptance 2019-10-11. Final version published as submitted by the authors. 